\title{
SOBRE LAZER E POSSIBILIDADES FORMATIVAS EM ADOLESCENTES QUE CUMPREM MEDIDAS SOCIOEDUCATIVAS
}

\author{
Kleber Tuxen Carneiro \\ Universidade Federal de Lavras, Lavras, Minas Gerais, Brasil \\ Maurício Bronzatto \\ Faculdade de Administração e Ciências Contábeis de São Roque, São Roque, São Paulo, Brasil \\ Eliasaf Rodrigues Assis \\ Faculdade de Administração e Ciências Contábeis de São Roque, São Roque, São Paulo, Brasil \\ Laiane Bronel Correa \\ Universidade do Estado de Mato Grosso, Cuiabá, Mato Grosso, Brasil
}

\begin{abstract}
Resumo
Este trabalho, de teor qualitativo, procurou conhecer a concepção de lazer de adolescentes que cumprem medidas socioeducativas e refletir sobre os benefícios formativos potencialmente presentes em suas práticas de lazer. A investigação contou com a participação de dez adolescentes da Unidade de Internação de Cáceres - MT. De acordo com os dados, para que o lazer seja um mecanismo de transformação cultural, é fundamental conhecer seus diferentes conteúdos e vivenciar suas inúmeras formas de expressão. Observou-se uma restrita oferta de experiência de formação para e pelo lazer. Concluiu-se que é possível pensar em possibilidades formativas por meio do lazer e em ações que visem expandir o restrito repertório desfrutado pelos adolescentes que cumprem medidas socioeducativas.
\end{abstract}

Palavras-chave: Lazer. Adolescência. Socioeducativo. Formação.

\section{Introdução}

Muito se tem dito a respeito da importância do lazer. Recorrente nos diferentes canais midiáticos, o tema está atrelado à ideia de qualidade de vida. No entanto, pouco se fala do lazer como espaço de formação humana ou de transformações culturais e sociais. Costumeiramente, o que se aborda é a instrumentalização do lazer como descanso para recuperação das forças produtivas.

Pelo prisma do descanso, o lazer apresenta uma função compensatória do desgaste das energias produzido pelo tempo de trabalho. Mas restringir seu conceito a uma forma de divertimento ou de ruptura da monotonia cotidiana reduz suas possibilidades e conteúdos.

Assim, justificar o lazer por meio da simples ocupação do tempo livre é um argumento que depaupera o fenômeno. Para Marcellino (1987, 2006), há outras possibilidades de lazer, além do descanso e divertimento, que abrangem o desenvolvimento pessoal e social. Logo, não se trata de negar a presença do lazer no descanso e no divertimento, mas de compreendêlo como "veículo e como objeto da educação", isto é, ver o lazer através de lentes críticas e lúdicas ${ }^{1}$ (MARCELLINO, 1987). Tal posicionamento se assenta em uma concepção de edu-

\footnotetext{
${ }^{1} \mathrm{O}$ termo lúdico tem sua origem na palavra latina "ludus", que pode ser compreendida como "jogo". Em nosso 
cação "do" e "para" o lazer, cujos desdobramentos reverberariam no enriquecimento de uma tomada de consciência crítica sobre a amplitude de suas manifestações, bem como no entendimento de seus conteúdos e práticas, principalmente aquelas relacionadas à cultura corporal de movimento ${ }^{2}$.

Essa concepção parece ressaltar tanto o aspecto salutar do lazer como a necessidade urgente de vivenciá-lo em sua integralidade, em especial quando se têm em vista adolescentes que cumprem medidas socioeducativas em condição de liberdade assistida (público-alvo da presente investigação). Segundo o ECA (BRASIL, 2008) e o Sistema Nacional de Atendimento Socioeducativo - SINASE (BRASIL, 2006), as medidas socioeducativas se assentam nos seguintes princípios: brevidade, excepcionalidade e respeito à condição peculiar de pessoa em desenvolvimento. Para tanto, propõem-se três eixos: Promoção, Defesa e Controle Social, através dos poderes Executivo, Legislativo e Judiciário e pela sociedade civil.

Dada a abrangência de cada eixo, para atender a um delineamento, este estudo se deteve no eixo da Promoção dos Direitos. É nele que se observa a política de atendimento aos direitos humanos de crianças e adolescentes por intermédio de serviços e programas inseridos em políticas públicas. Assim, esporte, cultura e lazer são componentes (ou deveriam ser) dos programas que executam a internação provisória e as medidas socioeducativas, propiciando aos internos acesso às programações culturais (teatro, literatura, dança, música, artes e atividades esportivas) e à aprendizagem de valores por meio dessas atividades (BRASIL, 2006).

É nessa perspectiva que se situa a presente investigação, cuja proposição teve um duplo objetivo: a) conhecer as práticas sociais relacionadas ao lazer existentes no contexto da privação de liberdade e b) compreender a concepção de lazer dos adolescentes que cumprem medidas socioeducativas no município de Cáceres - MT.

Para atender a esses objetivos, buscou-se identificar o perfil dos adolescentes que cumprem medidas socioeducativas na Unidade, bem como verificar o que indicam como conteúdos de lazer e se tais conteúdos, em seu modo de entender, contribuiriam para o próprio desenvolvimento pessoal, melhoramento da convivência social e reinserção na sociedade.

Tanto a oferta do lazer quanto a acessibilidade dos indivíduos a esse desfrute são, de modo geral, restritivas no município de Cáceres - MT (lócus da pequisa). Partimos, portanto, da hipótese de que tais restrições seriam mais acentuadas em uma unidade de medidas socioeducativas, o que demandou o levantamento de dados sobre as práticas de lazer a que os adolescentes têm acesso na unidade. Os resultados, como se verá, permitiram-nos entrever nestas atividades duas possibilidades bastante promissoras: 1) um espaço formativo que potencialize o desenvolvimento dos envolvidos e 2) intervenções pedagógicas que compreendam os diferentes conteúdos e práticas de lazer como um elemento facilitador de benefícios para a saúde, formação humana e transformação social.

\section{Uma breve historiografia do lazer}

O lazer como fenômeno possui uma complexidade de implicações filosóficas, sociológicas e psicológicas que torna, segundo Aguiar (2000), sua temática polêmica. A origem do lazer, em decorrência de sua íntima ligação com as formas de organização do trabalho ao longo das diferentes sociedades, é apresentada de forma controvertida por historiadores e soció-

entendimento, o conceito de lúdico refere-se a uma dimensão humana que evoca os sentimentos de liberdade e espontaneidade na construção da ação (CARNEIRO, 2015).

${ }^{2}$ Por cultura corporal de movimento, assumimos o mesmo entendimento de Betti (2013, p. 63): "[...] parcela da cultura geral que abrange as formas culturais que se vêm historicamente construindo, nos planos material e simbólico, mediante o exercício da motricidade humana - jogo, esporte, ginástica e práticas de aptidão física, atividades rítmicas/expressivas e dança, lutas/artes marciais, práticas alternativas". 
logos. Logo, nesta breve historiografia, percebem-se diferentes concepções históricas que perpassaram o fenômeno.

Ao longo da história, o surgimento do lazer esteve vinculado às formas de se divertir que eram importantes para a organização cotidiana da vida. Essas formas se substancializavam em diferentes espaços, como o trabalho, a busca pelo sagrado e a dinâmica da composição familiar, entre outros. Não havia uma abrupta distinção entre a diversão e o conjunto geral das outras atividades cotidianas, como se observa, por exemplo, em Carneiro (2015).

Segundo Dumazedier (1973), nas sociedades pré-industriais o trabalho obedecia ao ritmo natural da vida. As festas, ligadas ao culto e à tradição, não faziam uma acentuada distinção entre trabalho e tempo livre. Melo e Alves Júnior (2003) mencionam o uso relativamente recente da palavra lazer, que não fazia parte do discurso corrente no passado. Eram usadas outras formas linguísticas, que expressam ideia equivalente, tais como: diversão, prazer etc.

Segundo esses autores, o termo recebeu diferentes acepções ao longo da história, começando na Grécia Antiga, onde havia a redução do tempo de trabalho para o cultivo do tempo livre e da contemplação. Essa perspectiva valorizadora do momento de desocupação oportunizou o crescimento de outras dimensões da vida, fosse na arguição filosófica, na apreciação estética ou no aprofundamento da espiritualidade. Cabe destacar a diferenciação do lazer nas diferentes classes sociais. Enquanto a "elite" dedicava-se à contemplação, os escravos faziam o "trabalho sujo". Tal diferença era notada na compreensão de que o "[...] homem que possui tempo livre é livre, já que, para ser livre, um homem deve possuir tempo livre" (MELO; ALVES JUNIOR, 2003, p.3).

Já para os romanos da antiguidade, o trabalho não tinha uma conotação negativa. $O$ tempo do não trabalho, do ócio, passou a ser compreendido como regenerador, uma preparação do corpo e espírito para a volta ao trabalho. Na grande Roma, o tempo livre era aproveitado em forma de diversão popular, não sendo voltado apenas a uma classe social, como no caso da Grécia. No entanto, não havia a junção das classes: os "nobres" desenvolviam suas atividades, nas quais a reflexão era o elemento de destaque, enquanto que as classes menos abastadas eram "conduzidas" ao desfrutar de atividades que se restringiam aos grandes espetáculos. Evitava-se, assim, qualquer movimento que pudesse se voltar contra as políticas vigentes ou governantes (MELO; ALVES JUNIOR, 2003).

$\mathrm{Na}$ Idade Média, o tempo "livre" era visto pela população pobre como um tempo de descanso dos serviços e também um tempo de celebrar, o que ocorria nas festas e comemorações. Já para a nobreza, era o tempo de exibir o luxo, com a ostentação das riquezas, como se observa nas palavras de Melo e Alves Junior (2003, p. 5):

Para as camadas populares, não havia uma rígida divisão social do tempo, já que não havia uma separação categórica do tempo de trabalho e de não trabalho. Ou se trabalhava seguindo os desígnios e desejos dos nobres (caso dos servos), ou se seguia a dinâmica do tempo da natureza (caso dos que trabalhavam no plantio), ou se desfrutava de certa flexibilidade (caso dos artesãos e pequenos comerciantes).

No período de transição da Idade Média para a Idade Moderna, o modo de produção feudal entra em decadência, ao mesmo tempo em que as relações capitalistas de produção começavam a ser construídas. Tal transformação produziu diferentes desdobramentos para o lugar de ocupação do trabalho e do tempo livre. A separação nítida entre tempo, espaço de trabalho e lazer ocorre com a industrialização.

Os efeitos dessa mudança impactam abruptamente a sociedade moderna, produzindo uma excessiva exaltação ao trabalho e uma profunda desvalorização do não trabalho. Consequentemente, houve a diminuição dos espaços e formas de divertimentos populares (MELO; 
ALVES JUNIOR, 2003), o que conduz à compreensão de que o conceito de lazer, em alguma medida, é determinado pelas relações de trabalho e modo de produção de uma organização social e é concebido de forma distinta, dependendo da classe social em que o sujeito está inserido.

No contexto social nacional, de acordo com Camargo (1992), a industrialização, nos moldes da organização produtiva capitalista, começou no Brasil no final do século XIX. Após forte embate, a classe operária conseguiu a redução de sua jornada de trabalho, engendrando grande desconforto na classe dominante. $\mathrm{O}$ que se temia era que o uso do tempo livre encorajasse movimentos revolucionários ou estilos de vida perniciosos para a produtividade. Havia forte preocupação de que a população do Brasil, a exemplo do que acontecia na Inglaterra, se voltasse contra os ditames hegemônicos vigentes.

\section{Algumas concepções de lazer}

Elaborar uma definição de lazer é um grande desafio. Ao longo dos anos, não se apresentou um conceito específico que abarcasse a totalidade de sua dimensão. Vários autores analisaram o tema, em uma multiplicidade de referenciais teóricos e diferentes abordagens epistemológicas, o que produziu significados distintos.

Em comum, estabelece-se o que vem a seguir. Em suas origens etimológicas, a palavra lazer vem do latim licere, entendida como: "ser lícito, ser permitido, poder-se fazer". Nota-se aqui um "entrave" semântico, pois a mera palavra não define o fenômeno. Antes, denota a legalidade de seu desfrute, os limites de sua licitude diante do dever do trabalho.

Rolim (1989, p.51), na tentativa de compreensão do fenômeno, propôs uma subdivisão do lazer. Na perspectiva econômica, diferencia-se do que "é útil, rende, dá lucro". Já na perspectiva sociológica, denomina-se lazer o que ocorre em outro tempo que não o do trabalho profissional e afazeres domésticos, ainda que vivenciado em atividades sociopolíticas e religiosas. No aspecto psicológico, o lazer é um "estilo de comportamento" que caracteriza a maneira de agir do indivíduo frente a suas escolhas nas atividades livres. Por fim, a perspectiva psicossociológica delimita o lazer como tempo livre, regido pela liberdade para administração do descanso, das formas e conteúdos do ócio (ROLIM, 1989). Alguns estudiosos se opõem a essa divisão, indispondo-se com a fragmentação do fenômeno.

A favor dessa categorização, uma referência obrigatória para a conceituação de lazer é Dumazedier (1973). Segundo Requixa (1977), um dos conceitos fundamentais de lazer é proveniente de Joffre Dumazedier e está em sua obra Vers une civilization dulo isir? Nessa obra, Dumazedier (1973) inaugura uma teoria mais geral do que propriamente uma teoria do lazer e a denomina como a "Teoria da Decisão". Nela articulam-se três tipos de pensamento: o axiológico, o teleológico instrumental e o probabilístico.

No primeiro, busca-se resposta à pergunta "Por que é preciso fazer isto?". Em nome de que valores, de que filosofia, de que concepção do mundo? Por sua vez, no segundo, questionam-se as finalidades, os meios. E, por fim, no pensamento probabilístico, o objetivo é responder à seguinte questão: "Qual é, provavelmente, a situação na qual eu ajo e que age sobre mim e quais são os resultados prováveis que poderei obter?”.

Ainda outra definição interessante pode ser encontrada em Andrade (2001, p.21), segundo quem o lazer é caracterizado como "[...] um conjunto de fatos e circunstâncias [...] que se apresentam como isentos das pressões e das tensões, e podem afetar as atividades humanas individuais e grupais [...]." Para o autor, o lazer é uma atividade essencial à vida humana, resultando em equilíbrio, saúde e produtividade.

Já em Pedro (2005), encontramos outra definição. Segundo o autor, lazer denota uma autogestão do tempo livre, voltada a uma satisfação pessoal e melhora da qualidade de vida, 
como o bem-estar físico, mental e social. O lazer estaria intrinsecamente relacionado com o contentamento, vivenciado com livre vontade ou autonomia.

Tais benefícios apontados por Pedro (2005) também são descritos por Dumazedier (1973, p.30): "[...] a ação positiva do lazer sobre o indivíduo é de realçar os benefícios para a mente, para o físico, para a formação profissional e para a sua sociabilidade."

Para Marcellino (1987, 2006), o lazer excede a trivial promoção de descanso e divertimento. $\mathrm{O}$ autor compreende que nas diferentes práticas do lazer há oportunidades excepcionais de reflexão sobre pessoas, valores e as diferentes realidades experimentadas pelos que compartilham a experiência:

Assim, a admissão da importância do lazer na vida moderna significa considerá-lo como um tempo privilegiado para a vivência de valores que contribuam para mudanças de ordem moral e cultural. Mudanças necessárias para implementação de uma ordem social. [...] a busca do prazer no lazer, o que não impede sua caracterização como um dos canais de atuação, no plano cultural, tendo objetivos não meramente reformistas, mas que signifiquem mudanças radicais no plano social. (MARCELLINO, 1987, p. 40-41)

Esta sinalização de uma perspectiva formativa do lazer é valiosa para a presente pesquisa, pois desvela o entendimento do lazer dos adolescentes que cumprem medidas socioeducativas na cidade de Cáceres - MT.

\section{Aspectos metodológicos da pesquisa}

\section{Objetivo geral}

Compreender a concepção de lazer presente em adolescentes que cumprem medidas socioeducativas na Unidade de Internação de Cáceres - MT, a partir da identificação das práticas sociais relacionadas ao lazer existentes no contexto da privação de liberdade.

\section{Objetivos específicos}

Esta pesquisa tem como objetivos específicos:

i. Conhecer o perfil de adolescentes que cumprem medidas socioeducativas na Unidade de Internação de Cáceres-MT.

ii. Observar o que indicam como sendo conteúdos de lazer.

iii. Analisar se identificam nas práticas do lazer possibilidades de desenvolvimento pessoal e suas implicações para o melhoramento da convivência social e para a reinserção social.

\section{Justificativa}

Como mencionado na introdução deste artigo, é necessário superar a concepção que restringe o lazer ao descanso e divertimento. Antes, ele deve ser concebido como "veículo e como objeto da educação" (MARCELLINO, 1987), o que amplia suas possibilidades e o desfrute de seus conteúdos. O presente texto atende a uma necessidade de se conceituar de forma mais ampla o lazer como fenômeno.

Em se tratando de adolescentes que cumprem medidas socioeducativas em condição de liberdade assistida, tal concepção se torna ainda mais necessária, por duas razões em especial: 1) Como vimos, as medidas socioeducativas se assentam em três esferas de ação: Promoção, Defesa, Controle Social, segundo o ECA (BRASIL, 2008) e o Sistema Nacional de 
Atendimento Socioeducativo - SINASE (BRASIL, 2006). E o eixo da Promoção dos Direitos concebe no esporte, cultura e lazer um espaço potencialmente formativo (BRASIL, 2006), o que demandaria esse entendimento mais elaborado na abordagem e propagação dos conteúdos de lazer.

Já a segunda razão está atrelada a um traço marcante do lócus da pesquisa, o município de Cáceres - MT, onde há poucas opções de lazer. Os autores desta pesquisa foram motivados a investigar se a escassez de manifestações de lazer verificada neste município se reflete no funcionamento da unidade para o cumprimento de medidas socioeducativas. E, em caso afirmativo, em que grau isso acontece. Tal investigação compilaria dados objetivos que, futuramente, poderiam embasar melhorias, intervenções pedagógicas e ganhos na saúde, formação humana e transformação social.

\section{Método}

Esta pesquisa optou pela abordagem qualitativa, que atende com propriedade aos objetivos de absorver as informações apuradas com os relatos orais dos sujeitos participantes. Tal abordagem também permite correlacionar aspectos teóricos e elementos descritivos de forma a esclarecer alguns fenômenos tomados como objetos de estudo neste trabalho.

Ao mencionar os benefícios da uma pesquisa qualitativa/descritiva, Sampieri (2006, p. 102) observa que

Os estudos descritivos pretendem medir ou coletar informações de maneiras independente ou conjunta sobre os conceitos ou as variáveis a que se referem. Logo, podem integrar as medições ou informação de cada uma das variáveis ou conceitos para dizer como é e como se manifesta o fenômeno de interesse.

Estando, portanto, assentado sobre os fundamentos da abordagem qualitativa, este estudo, para preparação, sistematização e análise inferencial dos dados, lançou mão do método denominado Análise de Conteúdo (BARDIN, 1977; TRIVIÑOS, 1981; FRANCO, 2008).

A Análise de Conteúdo é entendida como um conjunto de técnicas de análise das comunicações. Seu campo de atuação é extremamente vasto e foi escolhida porque possibilita, de um modo sistemático, organizar os dados coletados de tal forma que as inferências comparativas, advindas de deduções lógicas, assumam um grau maior de segurança e pertinência em relação ao tema. Sua organização obedece a três etapas processuais:

- pré-análise;

- descrição analítica;

- interpretação inferencial.

A pré-análise é simplesmente a organização do material. Esta etapa visa determinar, por exemplo, como serão recolhidos os dados que serão analisados. Depois de uma leitura geral de todo o material, é o momento de: "[...] formular os objetivos gerais da pesquisa, as hipóteses amplas da mesma e determinar o corpus da investigação que não é outra coisa que a especificação do campo no qual os pesquisadores deviam fixar sua atenção" (SAMPIERI, 2006, p. 102).

A descrição analítica é o momento em que se realiza um estudo aprofundado sobre os documentos que formam o corpo do trabalho, balizando-se nas hipóteses e teorias de suporte. Nesta etapa, os procedimentos de codificação, classificação e categorização são básicos, pois permitem avançar na busca de sínteses coincidentes, divergentes e neutras, localizadas no interior das mensagens. 
Já na terceira etapa, caracterizada como interpretação inferencial, as reflexões iniciadas na fase anterior atingem maior intensidade. Não cabe neste método de pesquisa deter a atenção única e exclusivamente nos conteúdos manifestos, mas sim aprofundar sua análise, desvendando o conteúdo latente que eles certamente possuem.

\section{Local}

A pesquisa foi realizada no Centro Socioeducativo de Cáceres - MT, localizado na Rua das Margaridas, $\mathrm{s} / \mathrm{n}^{\mathrm{o}}$, bairro Jardim Padre Paulo.

\section{Participantes}

Participaram desta pesquisa 10 adolescentes que cumprem medidas socioeducativas na Unidade de Internação de Cáceres-MT, sendo todos voluntários e com idades que variam entre 15 e 18 anos.

\section{Materiais}

Para a coleta dos dados, foi aplicado um roteiro semiestruturado de perguntas, que se constitui como o principal instrumento da investigação. Também foram observados a rotina e o cotidiano dos pesquisados (com anotações em um diário de bordo), ao longo de dois meses (in loco). Além disso, periodicamente ocorriam diálogos entre os pesquisadores e os participantes, expediente que ajudou a entender alguns comportamentos e respostas apresentados pelos adolescentes pesquisados. Também foi necessário o contato com as diferentes instituições (socioeducativa e juizado da infância e juventude) para permissão e apresentação dos elementos constituintes da pesquisa.

A seguir, apresentam-se as categorias de análise e a discussão dos dados encontrados, com base nos constructos teóricos que subsidiaram o estudo.

O tempo destinado à pesquisa e à análise dos dados foi de aproximadamente três meses.

\section{Apresentação e discussão dos resultados}

Analisamos as respostas dos pesquisados, interpretando-as à luz do referencial teórico do início deste artigo. A discussão dos resultados ensejou três categorias de análise, em consonância com a estrutura do roteiro semiestruturado de pesquisa e a proposição metodológica adotada.

A composição das três categorias obedece à seguinte ordem: I - Quem são nossos pesquisados; II - Olhares acerca do lazer; III - Prerrogativas e possibilidades de lazer, no entendimento dos pesquisados.

\section{Perfil etário e escolar dos pesquisados}

A pesquisa contou com 10 adolescentes do gênero masculino que cumprem medidas socioeducativas na Unidade de Internação de Cáceres - MT. O contingente de 10 voluntários é suficiente, tendo em vista uma abordagem qualitativa em que o pesquisador volta-se para a busca do significado do fenômeno estudado e seu papel organizador nos seres humanos.

\section{A idade dos participantes}


As idades dos participantes variaram entre 15 e 18 anos, resultando na média de 16 anos e oito meses.

\section{O nível de escolaridade}

Todos os 10 participantes da pesquisa estão matriculados em uma unidade escolar, uma exigência prevista no ECA (BRASIL, 2008) e no Sistema Nacional de Atendimento Socioeducativo - SINASE (BRASIL, 2006) quando se cumprem medidas socioeducativas. Os adolescentes ocupam níveis e séries diferentes. Sua seriação está distante do que se espera de suas respectivas faixas etárias, como pode ser visualizado no gráfico a seguir:

Gráfico 01- Nível de escolaridade.

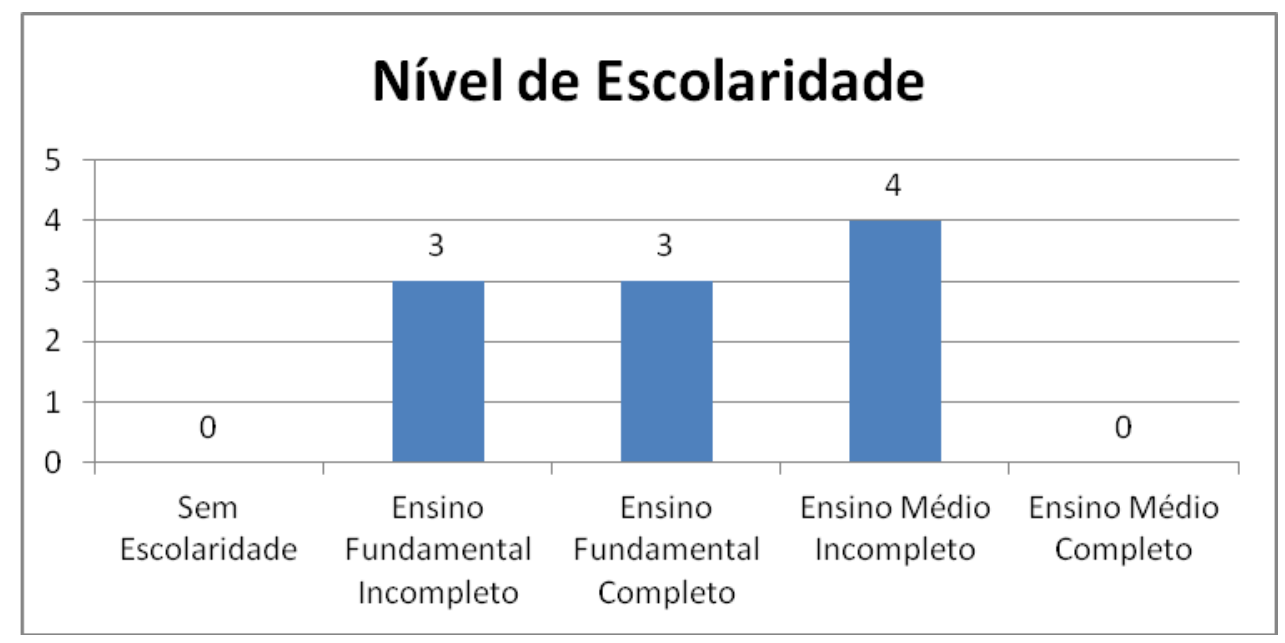

Fonte: Elaborado pelos autores a partir dos dados coletados, 2015.

Depreende-se dos dados acima que mais da metade dos participantes apresenta atraso na escolarização. Seis participantes encontram-se cursando (ou concluíram) o Ensino Fundamental II, quando deveriam estar cursando o Ensino Médio. Há uma aproximação com a realidade brasileira em que muitos jovens não ingressam no Ensino Médio, e o alto índice de absenteísmo do Ensino Fundamental II impossibilita o início da fase consecutiva do Ensino Médio.

Diante dos dados de escolarização dos pesquisados, conjecturávamos que encontraríamos um pensamento mais elaborado, acerca do lazer, naqueles com maior nível de escolarização. Supunha-se que o adolescente, ao apropriar-se dos saberes das disciplinas escolares, ampliasse seu entendimento sobre o mundo e suas relações, o que refletiria em sua compreensão sobre o lazer. No entanto, os entrevistados, na totalidade, apresentaram a mesma compreensão do fenômeno, independentemente do nível de escolarização, o que nos pareceu, no mínimo, inquietante. Impõe-se uma pergunta: privados dos saberes sobre o lazer, os internos poderiam desfrutar dos benefícios formativos do lazer a que Pedro (2005) e Dumazedier (1973) fazem referência? Como falar de medidas socioeducativas de ressocialização se tanto a escola regular quanto as unidades de internação, no que diz respeito ao lazer, têm deixado de fornecer condições de acesso e apropriação - desfrute que compõe um dos eixos das medidas socioeducativas?

Lembramos que para desfrutar da diversidade e qualidade do lazer é preciso que a educação possibilite tais vivências. A pouca oferta de experiência com os conteúdos empobrece a educação para e pelo lazer, como bem observou Pereira (1993, p. 7): 
O lazer está dependente da educação, dos padrões culturais, das oportunidades que a comunidade oferece, assim como das condições socioeconômicas da família. Assim sendo, o lazer reflete os valores culturais da família e do status que representa.

A próxima categoria de análise abordará a representação de lazer para os adolescentes e seus desdobramentos.

\section{Olhares acerca do lazer}

Nesta segunda categoria, procuramos investigar a percepção dos pesquisados sobre a importância de desfrutar de tempo para o lazer. Indagados sobre tal importância, os dez entrevistados foram categóricos em responder afirmativamente. Em busca de conhecer as justificativas para essa unanimidade, apresentamos quatro alternativas de respostas: a) Para promoção da saúde; b) Para ocupar a mente; c) Para o meu desenvolvimento; e d) Para minha formação humana. As opções foram escolhidas na proporção do gráfico a seguir:

Gráfico 02- Importância da prática do lazer.

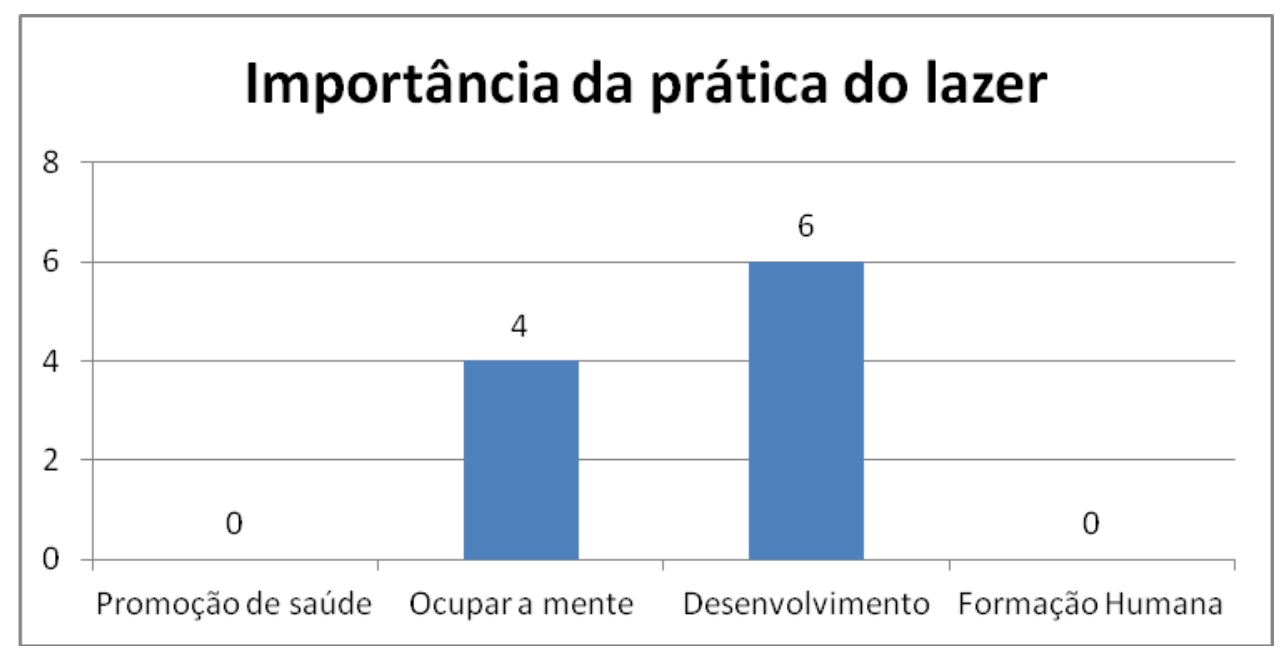

Fonte: Elaborado pelos autores, a partir dos dados coletados, 2015.

Observa-se um forte atrelamento do lazer ao desenvolvimento. Dos dez participantes, seis assinalaram que o lazer é importante para o seu desenvolvimento. No entanto, não há precisão sobre o que os sujeitos entendem por "desenvolvimento". Há diferentes entendimentos quanto ao termo.

Quatro dos entrevistados vinculam o lazer à ocupação da mente, uma decorrência lógica, pois as atividades de lazer implicam a ocupação do tempo. E a função de descanso está ligada ao aspecto compensatório do desgaste das energias, mitigando a fadiga mental. $\mathrm{O}$ divertimento é importante no processo de ruptura da monotonia cotidiana, interferindo na personalidade do indivíduo, ajudando-o a suportar as regras e as pressões da sociedade. Lembremos que essa conotação compensatória revela o que já foi dito na historiografia do lazer quando se avalia criticamente o processo de industrialização: há uma separação nítida entre tempo, espaço de trabalho e lazer. E os efeitos dessa estanqueidade atingem a sociedade moderna e contemporânea, produzindo a excessiva exaltação do trabalho e uma profunda desvalorização do não trabalho, ou ócio criativo, como advoga De Masi (2000).

Ademais, limitar o lazer a simples ocupação do tempo livre é um empobrecimento do fenômeno. Há uma perspectiva formativa no lazer que não foi apontada por nenhum de nos- 
sos entrevistados. Como probabilidade, atribuímos a ausência de alusões quanto aos aspectos formativos do lazer à baixa frequência da interação com essa dimensão do fenômeno pelos adolescentes entrevistados.

Importa que o indivíduo atente para as necessidades presentes no uso de seu tempo livre, ocupando-se de atividades que promovam possibilidades de crescimento pessoal e social. Nessa ótica, a próxima categoria de análise pretende compreender como os entrevistados percebem os diferentes conteúdos do lazer.

\section{Prerrogativas e possibilidades de lazer, no entendimento dos pesquisados}

Nesta categoria, tentamos conhecer quais seriam os conteúdos do lazer que estão acessíveis aos entrevistados, quais são os mais usufruídos e quais são aqueles de que mais gostariam de desfrutar. Para a construção desses dados, valemo-nos tanto das respostas extraídas do roteiro semiestruturado de perguntas quanto das observações realizadas in loco.

Dois agrupamentos de respostas foram encontrados. De acordo com o primeiro, a maioria afirma que tem acesso ao lazer e que este está atrelado às práticas esportivas e à atividade física. O lazer desfrutado por eles nos dois espaços (isto é: escola e unidade de internação) se restringe a isso, o que nos permite inferir que há uma restrita oferta de lazer, com forte potencial nas práticas esportivas, presentes, inclusive, na unidade de internação. Convém lembrar a advertência de Marcellino (2006), que acentua que as atividades de lazer devem atender às pessoas nos diferentes segmentos da vida. A oferta de diferentes tipos de lazer possibilita que as pessoas conheçam os conteúdos que melhor atendam seus interesses.

Quanto ao segundo agrupamento, os entrevistados restringem suas práticas de lazer à televisão, que permanece ligada boa parte do dia, mesmo quando não há telespectadores. A despeito da possibilidade instrutiva dos canais midiáticos, reduzir as diferentes possibilidades de lazer a uma condição passiva de telespectador parece limitar e depreciar as potencialidades formativas do lazer.

Salientamos, ainda, que, embora as perguntas fossem de múltipla escolha, havia espaço para que os participantes esboçassem outras alternativas, o que nenhum deles fez. Concluise que uma escassa oferta de possibilidades de lazer depaupera seus potenciais formativos, enfraquecendo as vivências quanto à diversidade de conteúdos de lazer possíveis. Indo além das respostas às entrevistas, a observação do cotidiano dos adolescentes também corrobora a escassez de alternativas de lazer.

A fim de refletir sobre a expansão da diversidade dos conteúdos de lazer, elaboramos, para a terceira e última categoria, a questão a seguir: "Se pudesse escolher uma atividade de lazer que nunca vivenciou, qual você escolheria? Por que optou por ela?"

\section{Lazer desejado}

Dos dez participantes, dois não apresentaram predileções. Os outros oito indicaram como lazer desejado uma prática esportiva, o que sinaliza a supremacia dessa modalidade. Dentre eles, dois mencionam interesse em aprender basquetebol, curiosamente um conteúdo frequente na Educação Física Escolar. Há reais possibilidades para ensinar esse esporte, inclusive no interior do espaço de reclusão. Como nunca tiveram contato com ela, é possível que as restrições na oferta de conteúdos de lazer ocorram desde sua escolarização, pois, como disciplina curricular, as aulas de Educação Física poderiam ter possibilitado a aprendizagem e experiências com o basquetebol.

Uma resposta interessante foi a do entrevistado cujo lazer desejado era a prática do "Golfe, por nunca ter jogado e também por curiosidade". Algo um tanto surpreendente, considerando que a modalidade não é culturalmente propagada no país. Outros três escolheram as 
lutas (capoeira e boxe), um dos entrevistados mencionou o atletismo, e um outro, a natação. Ora, todas essas modalidades apresentam-se como constituintes da cultura corporal de movimento. Causa estranheza que esses adolescentes tenham sido privados desses conhecimentos que são constituintes dos conteúdos da Educação Física e que deveriam constar nos programas de medidas socioeducativas.

Extraem-se das respostas apresentadas para a presente categoria três reflexões pontuais: 1) Há um expressivo anseio pelos saberes constitutivos da cultura corporal de movimento - esportes, jogo, danças, lutas etc. - como conteúdos do lazer. A atmosfera produzida por meio dessas vivências é um importante componente formativo para adolescentes que cumprem medidas socioeducativas. Leiro (2006) e Marcellino (1987) advogam que o lazer está intrinsecamente vinculado à educação, sendo necessário considerá-lo como um espaço potencialmente formativo, por meio das práticas corporais; 2) Há necessidade de uma educação formal e informal que oportunize essa experimentação, uma vez que a falta de oferta de experiências com diferentes conteúdos empobrece a educação pelo e para o lazer; 3) A oferta de lazer deve contemplar um repertório de possibilidades, considerando diferentes interesses, como o artístico, o intelectual, o físico, os manuais, o turístico ou o social, todos propostos por Marcellino (2006).

\section{Considerações finais}

Ao entrevistar adolescentes que passam por medidas socioeducativas, procurou-se também, observando in loco, registrar suas percepções, que retratam o lazer como atividade esportiva ou ocupação da mente. A melhoria do desenvolvimento é citada pelos sujeitos de forma vaga, validada mais em sua dimensão física do que em suas conotações com a totalidade da formação humana. A perspectiva formativa no lazer não foi apontada por nenhum dos entrevistados, muito provavelmente em razão de uma história de privação quanto ao envolvimento com essa dimensão do fenômeno. De forma majoritária entre os entrevistados, há um evidente empobrecimento das concepções acerca dos conteúdos do lazer, em especial quanto àquelas vivências que aprimorariam sua ressocialização.

Conclui-se que uma escassa oferta de possibilidades de lazer, seja por meio do ensino formal ou informal, seja em suas trajetórias na escola ou na unidade de internação, debilita seus potenciais formativos. A escassez de uma experiência com os conteúdos de lazer, registrada nas respostas às entrevistas, é corroborada pela observação do cotidiano dos adolescentes. $\mathrm{O}$ uso institucional do lazer é meramente para ocupação do tempo livre e da mente. Como não há variedade, mesmo esses objetivos acabam comprometidos pela monotonia e pelo tédio.

Os resultados da pesquisa, longe de exaurirem o tema, demandam e podem possibilitar futuros estudos, em especial sobre lazer e ressocialização. Novos recortes poderiam sugerir, a partir da presente análise, tanto a diversificação das práticas de lazer quanto a necessidade de políticas públicas que favorecessem a devida formação dos colaboradores e internos de unidades de medidas socioeducativas, priorizando o conhecimento dos conteúdos do lazer. $\mathrm{E}$ que o lazer, enquanto vivência, ultrapasse a função (necessária, mas não suficiente) de ocupação da mente e contemple o desenvolvimento do caráter social e crítico - indispensável para que as medidas socioeducativas contribuam para a reinserção do indivíduo em uma sociedade justa e humanizada.

\section{ABOUT LEISURE AND FORMATIVE POSSIBILITIES IN ADOLESCENTS WHO MEET EDUCATIONAL MEASURES}

\section{Abstract}


This work, qualitative content, sought to ascertain the notions of leisure adolescents who fulfill socio-educational measures and reflect on the benefits potentially present in their leisure activities. The research counted on the participation of ten adolescents fron inpatient unit of Cáceres - MT. According to the data, for the leisure be one cultural transformation engine, is essential to know their many contents and experience its various forms of expression. A limited supply of training experience to and through the leisure was observed. It is concluded that it is possible to think of training opportunities through leisure and actions that aim to expand the restricted repertoire enjoyed by adolescents who meet social and educational measures. Keywords: Leisure. Adolescence. Social-educational. Formation.

\section{SOBRE OCIO Y FORMATIVOS POSIBILIDADES EN ADOLESCENTES QUE CUMPLEN CON MEDIDAS EDUCATIVAS}

\section{Resumen}

Esta obra, de contenido cualitativo, trató de averiguar las nociones de adolescentes de ocio que cumplen medidas socioeducativas y reflexionar sobre los beneficios potencialmente presentes en sus actividades de ocio. La investigación contó con la participación de diez adolescentes de unidad de internación de Cáceres - MT. Según los datos, para el ocio sea un motor de transformación cultural, es fundamental conocer sus muchos contenidos y la experiencia de sus diferentes formas de expresión. Se observó un suministro limitado de experiencia de capacitación para y por el ocio. Se concluye de que es posible pensar en las oportunidades de capacitación a través del ocio y las acciones que tienen como objetivo ampliar el repertorio restringido disfrutado por los adolescentes que cumplen medidas socio-educativas.

Palabras clave: Ocio. Adolescencia. Socialeducational. Formación.

\section{Referências}

ANDRADE, J. V. de. Lazer: Princípios, tipos e formas na vida e no trabalho. Belo Horizonte: Autêntica, 2001.

BARDIN, L. Análise de conteúdo. Lisboa: edições 70, 1977.

BETTI, M. Educação Física Escolar: ensino e pesquisa-ação. 2. ed. Ijuí: Editora Ijuí, 2013. BRASIL. Sistema Nacional de Atendimento Socioeducativo - SINASE/ Secretaria Especial de Direitos Humanos. Brasília: CONANDA, 2006.

BRASIL. Estatuto da Criança e do Adolescente (1990). 6ª ed. Brasília: Câmara dos Deputados, Coordenação de Publicações, 2008.

CAMARGO, L. O. L. O que é lazer. 3 ed. São Paulo: Ed. Brasiliense, 1992.

CARNEIRO, K. T. POR UMA MEMÓRIA DO JOGO: a presença do jogo na infância das décadas de 20 e 30. 2015. 273f. Tese (Doutorado em Educação Escolar). Faculdade de Ciências e Letras, Universidade Estadual Paulista, Araraquara, 2015.

DE MASI, D. O ócio criativo. Rio de Janeiro: Sextante (2000).

DUMAZEDIER, J. Lazer e cultura popular. Tradução de Maria de Lourdes S. Machado. São Paulo: Perspectiva, 1973. 
FERREIRA, T. H. S.; FARIAS, M. A.; SILVARES, E. F. de M. Adolescência através dos Séculos. In: Psicologia: Teoria e Pesquisa. Abr-Jun 2010, Vol.26, n.2, p. 227-234.

FRANCO, M. L. P. B. Análise do conteúdo. 3ed. Brasília: Liber Livro Editora, 2008.

GROSSMAM, E. A adolescência através dos tempos. In: La Adolescência latinoamericana. v.1 n. 2. Set. 1998. p.68-74. Disponível em: <http://raladolec.bvs.br/pdf/ral/v1n2/p03v01n2.pdf.> Acesso 12/09/2014.

LEIRO, A. C. R. Educação, lazer e cultura corporal. Presente! (Centro de Estudos e Assessoria Pedagógica), v. 53, p. 47-53, 2006.

MARCELINO, N. C. Políticas públicas de esporte e lazer: o papel do poder público e do terceiro setor. In: MAIA, L. F. dos S.; OLIVEIRA, M. V. de F.; MENDES, M. I. B. de S. Org. Poder Público, terceiro setor e controle social: interfaces na construção de políticas de esporte e lazer. Natal, RN: Ed. CEFET-RN, 2007. p.9-24.

MARCELINO, N. C. Estudos do lazer: uma introdução. 4.ed. Campinas, SP: Autores Associados, 2006.

MARCELINO, N. C. Lazer e Educação. 11ed. Campinas, SP: Papirus, 1987.

MELO, V. A.; ALVEZ JUNIOR, E. de D. Introdução ao Lazer. São Paulo: Manole, 2003.

PEDRO, C. S. F. Identificação das Práticas de Lazer: Estudo com crianças do $1 .^{\circ}$ Ciclo do Ensino Básico de Valpaços. 2005. 163f. Mestrado em Estudos da Criança - Educação Física e Lazer- Universidade do Minho, Instituto de Estudos da Criança.

PEREIRA. B. O. O lazer e desenvolvimento humano. Jornal de psicologia, Braga , 1993.

REQUIXA, R. O lazer no Brasil. São Paulo: Brasiliense, 1977.

As Dimensões do Lazer. São Paulo: Sesc / Celazer, 1974.

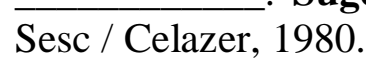

Sugestões de diretrizes para uma política nacional de lazer. São Paulo:

ROLIM, L. C. Educação e Lazer, a aprendizagem permanente. São Paulo: Ed. Ática, 1989.

SAMPIERI, R. H. Metodologia de pesquisa. 3. ed. São Paulo: McGraw-Hill, 2006.

SILVA D. A. M.; et al. Gestão de Políticas Públicas de esporte e lazer: princípios e pressupostos teóricos. Brasília: Gráfica e Editora Ideal, 2011.

TRIVIÑOS, A. N. S. Introdução à pesquisa em Ciências Sociais: a pesquisa qualitativa em educação. São Paulo: Atlas, 1987. 
Recebido em: 03/02/2016

Revisado em: 12/11/2016

Aprovado em: 12/11/2016

Endereço para correspondência:

kleber2910@gmail.com

Kleber Tuxen Carneiro

Universidade Federal de Lavras

Av. Doutor Sylvio Menicucci, 1001

Kennedy, Lavras - MG, 37200-000 